Hjarvard, S. (2008) The mediatization of society: A theory of the media as agents of social and cultural change. Nordicom Review, vol. 29 (2), pp. 105-134.

Masuda, Y. (1981) The Information Society as Post-Industrial Society. Washington, D.C., World Future Society. 171 p.

Picard, R. (2011) Mapping digital media: digitalization and media business models. Open Society Foundations [online] Available at: https://www.opensocietyfoundations.org/sites/default/files/digitization-media-business-models-20110721.pdf (access date 10.10.2018).

Porat, M. (1977) The Information Economy. Washington, DC., US Department of Commerce. 490 p.

Submission date: 12.10 .2018 .

Полуэхтова Ирина Анатольевна - доктор социологических наук, профессор, профессор кафедры теории и экономики средств массовой информации факультета журналистики Московского государственного университета им. М. В. Аомоносова; руководитель отдела социологических исследований Аепартамента аналитических исследований Новой сервисной компании (НСК). Адрес: 125009, Россия, г. Москва, ул. Моховая, д. 9, стр. 1. Тел.: +7 (495) 629-44-40. Эл. aspec: ipoluekhtova@gmail.com

Poluekhtova Irina Anatolyevna, Doctor of Social Science, Professor, Professor, Department of the Theory and Economics of Media, Faculty of Journalism, Lomonosov Moscow State University; Head, Office of Social Research, Department of Analytical Research, New Service Company (NSC). Postal address: 9, Bldg. 1, Mokhovaya St., Moscow, Russian Federation, 125009. Tel.: +7 (495) 629-44-40. E-mail: ipoluekhtova@gmail.com

DOI 10.17805/zpu.2018.4.8

\title{
Проектный подход в решении проблем прекаризации занятости современной молодежи
}

\author{
Н. В. ФЕДОРОВА, М. М. КОВРИЖКИНА \\ МОСКОВСКИЙ ГУМАНИТАРНЫЙ УНИВЕРСИТЕТ
}

В статье анализируется проблема временной занятости (прекаризации) молодежи России, которая распространилась сегодня на рынке труда. При этом молодежь не рассматривается как единое поколение, в ее составе есть различные поколенческие группы. Выделяются следующие категории работающей молодежи: стабильно занятые, успешные фрилансеры, работающие низкооплачиваемые молодые специалисты и прекаризованная группа молодежи. Заработков молодежи, относящейся к последней группе, хватает на выживание, но не более того. Молодежь этой категории не может сменить профессию или место жительства, она недостаточно грамотна с правовой точки зрения, чтобы найти работу и заключить хороший контракт. Выживание ей обеспечивают родители или более успешные родственники.

Главная особенность этой группы - восприятие рынка труда как безусловно враждебного к ним. В отличие от молодых людей с низким доходом прошлого, современные представители низшей прекаризованной группы молодежи менее склонны к асоциальному поведению, проявляя низкую политическую и криминальную активность.

Прекаризацию молодежи как явление можно связать с развитием острых поколенческих конфликтов, действующих в трех социальных плоскостях: в системе образования (между преподавателями и обучающимися), на рынке труда (между работодателями и молодыми специалистами) и в среде самой молодежи (внутриролевой конфликт). 
Общей рекомендацией может стать не только выработка профессиональных компетенций в рамках образовательного процесса, но и проведение мероприятий со стороны работодателей. Это касается разработки системы поиска перспективных выпускников и организации стажировок. Успешной показывает себя практика взаимодействия работодателей с учебными заведениями для целевой подготовки будущих сотрудников.

В целом прекаризация молодежи может быть расценена как негативное явление современного рынка труда, устранение которого можно решить с помощью проектного менеджмнта на государственном уровне. Негативное влияние ее может быть снижено за счет разработки проектов трансформации образовательного процесса в учебных заведениях и более тесной работы с будущими работодателями. Такое взаимодействие усиливается через деятельность профессиональных и бизнес-сообществ по созданию и корректировке профессиональных стандартов и развитию у молодых специалистов надпрофессиональных компетенций, что в конечном счете позволит преодолеть прекаризацию занятости молодежи.

Ключевые слова: проектный подход; проект; прекаризация; молодежь; миллениалы; рынок труда, занятость

\section{ВВЕАЕНИЕ}

Э кономика России зависит от влияния различных факторов и формируется в определенных условиях. Это касается и сегодняшнего этапа ее развития. К таким факторам можно отнести политические, экономические, технологические, социальные и проч. Мы сконцентрируемся в статье только на социальных факторах, которые позволяют определить демографическую структуру населения и тенденции его развития, нормы, обычаи и ценности, отношение к работе, темпы роста населения, но все это будет в той или иной мере определять состояние рынка труда и численность трудоспособного населения (Бобков и др., 2015: 12; Федорова, 2015: Электронный ресурс). В частности, обратимся к рынку труда молодежи, людей возрастом от 18 до 30 лет (иногда до 35 лет), хотя Всемирная организация здравоохранения определяет возраст молодости с 19 до 44 лет (Калинюк, 1985: 56).

Известно, что на рынке труда сегодня происходят трансформационные явления, которые затрагивают так или иначе отдельные категории персонала. К таким трансформационным явлениям можно отнести прекаризацию (от англ. precarious и лат. precarium - сомнительный, опасный, рискованный, негарантированный, нестабильный, стоящий на песке) занятости, т. е. определенную уязвимость работников перед работодателем, снижения которой можно добиться с помощью проектного менеджмента.

Молодежь, как правило, востребована на рынке труда, но в отношении ее также проявляются элементы нестабильной занятости. Современная молодежь, как правило, характеризуется различным отношением к жизни. Она имеет формирующиеся или сформированные интересы и ценности, поэтому необходимо выявить отдельные категории молодежи по их отношению к рынку труда. С одной стороны, необходимо определить проблемы, с которыми она сталкивается на нем. С другой стороны, требует пристального внимания и поведение работодателя, его ожидания от молодых специалистов и работников, выходящих на рынок труда. Эти вопросам и будет уделено внимание в статье.

Основными признаки молодежи как социальной категории являются следующие: поиск идентификации в жизни, включая частную жизнь, выбор профессии; высокая социальная мобильность; активное обучение, социализация в различных социальных группах; активизация взаимодействия с социальными институтами в качестве самостоятельного субъекта; тяжелое эмоциональное состояние из-за неуверенности и недооценки собственных сил; высокая межпоколенная мобильность. 
Различные направления и объекты исследований, в том числе новые явления на рынке труда, поставили перед научным сообществом много вопросов. Можно выделить новые явления, характеризующие сегодняшнее положение. К ним относятся развитие современных IT-технологий, диджитализация экономики и социальных процессов. Молодежь уже не считается единым поколением, в ее составе рассматриваются различные поколенческие группы. В обществе в целом и у молодежи в частности меняется отношение к труду, постоянной занятости, самостоятельности. Молодежь становится функциональным ресурсом для работодателей в большей степени, чем было предыдущее поколение, в силу усиления специализации и профилизации профессиональной деятельности. Рассмотрим более подробно эти явления.

\section{СОВРЕМЕННЫЕ ТЕНАЕНЦИИ РАЗВИТИЯ ОБЩЕСТВА И ТЕХНОАОГИЙ}

Новое поколение молодежи, так называемых миллениалов, связано с развитием IT-технологий, с глобализацией, особенностями развития экономик в различных странах, мобильностью, что требует от нее наличия высоких адаптационных навыков. Современное развитие компьютеризации процессов производства товаров, оказания услуг и управления, телекоммуникации, социальных сетей приводят к возникновению коммуникаций, позволяющих людям общаться в двух пространствах - виртуальном и реальном. Это приводит не только к росту скорости общения, обмена мнениями, но и вызывает к жизни новые нестандартные формы занятости, развивает спрос на новые профессии высокой квалификации, а также требует знаний в области информатики и современных средств коммуникации.

На сегодняшний день не выработаны единые методологические подходы к четкому определению понятия и границ поколения, факторов, влияющих на сложившуюся ситуацию с занятостью молодежи, и последствий, влияющих в конечном итоге на уровень ее безработицы и занятости. Однако это не умаляет значения изучения этих вопросов научным сообществом.

И в первую очередь речь идет о поколении NEET, или поколении «ни-ни» (англ. Not in Education, Employment or Training), к которому относят молодых людей, не занятых на рынке труда и не получающих образование.

Часть исследователей придерживается мнения, что на появление нового поколения молодежи влияет ее низкий уровень развития (Зудина, 2017: Электронный ресурс). Аругие говорят о появлении такого поколения в развитых странах за счет притока мигрантов (Жвитиашвили, 2016; Elder, 2015: Электронный ресурс и др.). Однако, мы считаем, что это явление связано не только с притоком мигрантов в развитые страны, но и с развитием современного этапа техники и технологии, когда выпускник, приходящий в организацию, сталкивается с высокотехнологичным производством, и полученных знаний не хватает для высокопроизводительного труда.

В научной литературе пока нет единого мнения о категориях поколения NEET, поэтому классификация групп молодежи поколения NEET и их характеристика требуют дополнительного уточнения. Сегодня ученые и специалисты различных стран выделяют следующие категории поколения NEET.

1. «Клубничное» поколение - это молодежь, родившаяся после 1981 и до 1990 г., которая не выдерживает социального давления или тяжелого труда и перестает работать (Schott, 2008: Электронный ресурс; Chou, 2005: Электронный ресурс).

2. Поколение фритеров - это молодежь, которая живет от непостоянного заработка и работает неполный рабочий день или работает фрилансерами, либо вообще 
не работает (исключение - домохозяйки и студенты), либо молодые люди, осознанно не желающие работать после окончания школы. Как правило, фритер работает на таких рабочих местах, которые требуют низкой квалификации.

3. Миллениалы, или поколение «Ү» (поколение «игрек»; «некст», «сетевое» поколение, миллениты, эхо-бумеры), - это молодежь, родившаяся после 1981 г. и активно использующая в жизни цифровые технологии, в том числе в трудовой деятельности.

4. Поколение «Z», к которому относят молодых людей, родившихся в первом десятилетии XXI в. Это поколение является наименее изученным, так как молодые люди только достигли дееспособного возраста и пока еще не успели проявить себя в полной мере. Однако однозначно можно сказать, что у них высока адаптационная способность к применению всевозможных гаджетов и интернет-программ, они активно используют современные технологии в обучении и общении.

5. Поколение «А» (родившиеся после 2010 г.), которое начали выделять как следующее за поколением «Z». Исследователи высказывают предположения, что рожденные после 2010 г. не будут знать, что такое нехватка товаров, они практически с рождения приучены к беспроводным технологиям и глобальной информированности.

6. Хикикомори (японский термин) - молодежь, которая отказывается от социальной жизни, она предпочитает уединение и добровольно отказывается от социальной жизни, не работает и живет на иждивении родственников.

Если первую, вторую и шестую группы отличает девиантное поведение, редкое и осуждаемое обществом, то миллениалы, поколение «Z» и поколение «A» - категории возрастные. Безусловно, даже принадлежность к определенной возрастной категории не может быть полноценным критерием для классификации положения молодежи на рынке труда. Отдельные качества различаются в зависимости от социальной среды, в которой происходила социализация конкретного молодого человека. Также имеет значение его социальное происхождение, особенности воспитания, место жительства и материальные возможности семьи, в которой он вырос.

\section{КААССИФИКАЦИЯ МОАОАЕЖИ}

Нам представляется возможным выделить следующие категории молодежи как категории рынка труда (см. таблицу).

Аанная классификация может быть использована, в том числе, при найме молодых специалистов в организацию. Рынок труда в свою очередь может применять эти классификационные категории для оценки качества выпускников, стажеров, потенциальных кандидатов на перевод, командировку за рубеж и т. п.

Аействующий рынок труда создает объективные условия существования молодежи, ее развития в качестве специалистов, а главное - характеристики отдельных групп молодежи не только в качестве субъектов, но и в качестве объектов влияния регуляторов и крупных игроков рынка: служб занятости, налоговых служб, финансовых организаций, контролирующих органов.

\section{КААССИФИКАЦИЯ РАБОТАЮЩЕЙ МОАОАЕЖИ}

Можно выделить четыре категории работающей молодежи и оценить сильные и слабые стороны каждой из них.

1. Стабильно занятые (Стэндинг, 2014: Электронный ресурс). Это стажеры или молодые специалисты крупных и средних по масштабу предприятий. Они планируют свои долгосрочные цели, используя сильные стороны миллениалов - креативность, техни- 
КААССИФИКАЦИЯ МО ОАЕЖИ КАК КАТЕГОРИИ РЫНКА ТРУАА CLASSIFICATION OF YOUNG PEOPLE AS CATEGORIES OF THE LABOUR MARKET

\begin{tabular}{|c|c|}
\hline $\begin{array}{c}\text { Классификачионный } \\
\text { признак }\end{array}$ & Классификачия \\
\hline Наличие занятости & $\begin{array}{l}\text { - Учащиеся (дневная, вечерняя, заочная форма); } \\
\text { - работающие временно; } \\
\text { - работающие постоянно; } \\
\text { - не учащиеся, но готовые начать работать или учиться; } \\
\text { - фрикционные безработные, в том числе по семейным причинам; } \\
\text { - маргинальные безработные }\end{array}$ \\
\hline Наличие дохода & $\begin{array}{l}\text { - Имеющие собственный доход (ниже прожиточного минимума, } \\
\text { выше прожиточного минимума); } \\
\text { - имеющие постоянной или разовый доход; } \\
\text { - не имеющие дохода }\end{array}$ \\
\hline $\begin{array}{l}\text { Наличие семейных обязан- } \\
\text { ностей и поддержки }\end{array}$ & $\begin{array}{l}\text { - Одинокие, без обязанностей и поддержки; } \\
\text { - имеющие поддержку от супругов или родителей; } \\
\text { - оказывающие поддержку супругам, детям или родителям }\end{array}$ \\
\hline $\begin{array}{l}\text { Наличие профессиональ- } \\
\text { ного образования }\end{array}$ & $\begin{array}{l}\text { - Имеющие профессиональное образование; } \\
\text { - в процессе получения образования имеющие возможность } \\
\text { проходить стажировки и начать трудовую деятельность; } \\
\text { - не имеющие профессионального образования }\end{array}$ \\
\hline $\begin{array}{l}\text { Наличие трудовых навыков, } \\
\text { соответствующих данной } \\
\text { работе }\end{array}$ & $\begin{array}{l}\text { - Имеющие трудовые навыки; } \\
\text { - не имеющие трудовых навыков }\end{array}$ \\
\hline $\begin{array}{l}\text { Наличие дополнительных } \\
\text { навыков и знаний, не отно- } \\
\text { сящихся напрямую к вы- } \\
\text { бранной работе }\end{array}$ & $\begin{array}{l}\text { - Имеющие дополнительные навыки и знания, не относящиеся } \\
\text { напрямую к выбранной работе; } \\
\text { - не имеющие дополнительных навыков и знаний, } \\
\text { не относящихся напрямую к выбранной работе }\end{array}$ \\
\hline $\begin{array}{l}\text { Готовность к переезду } \\
\text { к новой работе или } \\
\text { на новый проект }\end{array}$ & $\begin{array}{l}\text { - Готовы к переезду; } \\
\text { - готовы к вахтовой или иной циклической работе; } \\
\text { - готовы к длительным поездкам на работу; } \\
\text { - не готовы к переезду и поездкам свыше } 1,5 \text { часов до работы }\end{array}$ \\
\hline $\begin{array}{l}\text { Наличие ограничений, } \\
\text { связанных с возможностью } \\
\text { трудоустройства }\end{array}$ & $\begin{array}{l}\text { - Знание языка; } \\
\text { - владение ПК; } \\
\text { - ограничения по здоровью, в том числе психическому }\end{array}$ \\
\hline
\end{tabular}

ческую грамотность и коммуникабельность. Такие молодые люди заинтересованы в служебном росте, социальном пакете, профессиональном совершенствовании, хорошей кредитной истории, высоких годовых бонусах. Слабая сторона связана с системными кризисами в современной әкономике: рыночные спады вызывают массовые сокращения, и тщательно выверенные карьерные планы могут быть нарушены сокращением штата. Тем не менее это наиболее устойчивая категория работающей молодежи; буду- 
щий средний класс. Они заключают своеобразный социальный контракт с работодателем, обменивая лояльность на устойчивость материального и социального положения.

2. Успешные фрилансеры - свободные программисты и разработчики, блогеры, владельцы собственного малого бизнеса, консультанты в различных отраслях, творческие работники (фотографы, дизайнеры), высокооплачиваемые самозанятые работники сферы услуг. Их занятость неустойчива, но высокие заработки позволяют удовлетворять потребности не только в собственной экономической безопасности, но и в дополнительном образовании и дорогостоящем досуге. Они не внедрены в офисную субкультуру, но тесно с ней сотрудничают, выполняя краткосрочные контракты. Прекаризация этой группы растет в случае болезни или падения количества крупных заказов, они менее социально защищены, чем стабильно занятые. Сильной стороной этой категории является высокая мобильность, креативность и активный творческий поиск. Они идеальные потребители современных товаров и услуг, так как располагают большим количеством свободного времени по сравнению с первой категорией. Также сильная сторона успешных фрилансеров на рынке труда - широкие деловые связи, возможность совмещения нескольких проектов или работ.

3. Работающие низкооплачиваемые молодые специалисты. Их занятость относительно устойчива в стадии рыночного подъема, однако находится под угрозой в условиях спада. Им недоступны крупные траты, такие как платное образование, поэтому слабое место этой категории - сложная реакция на изменение рынка труда, появление потребности в новых компетенциях. Прекаризация этой категории молодежи весьма вероятна. Более того, они не имеют комфортных каналов мобильности, в случае переезда или смены профессии им придется долгое время мириться с низким заработком и отсутствием социальных гарантий. Однако это самая массовая категория занятой молодежи, особенно в небольших городах и удаленных от столицы регионах. Свое материальное положение они могут подкрепить за счет приусадебного хозяйства и унаследованного имущества. Они маломобильны, что делает их идеальными исполнителями отдельных видов работ по месту жительства и в организации. К данной категории относятся сотрудники сферы услуг, бюджетной сферы, рабочий класс.

4. Низшая прекаризованная группа молодежи - это временно занятые молодые люди. Их заработков хватает на выживание, но не более того. Они не смогут сменить профессию или место жительства, к тому же они недостаточно грамотны с правовой точки зрения, чтобы найти работу и заключить хороший контракт. Выживание этой категории обеспечивают родители или более успешные родственники. Главная особенность этой группы - восприятие рынка труда как безусловно враждебного к ним. В отличие от молодых людей с низким доходом прошлого, современные представители низшей прекаризованной группы молодежи менее склонны к асоциальному поведению, проявляя низкую политическую и криминальную активность. Это преимущество дает им возможность досуга в виде сетевой и спортивной активности, в какой-то степени они могут стать даже частью гражданского общества, участвуя в экологических и других общественно полезных мероприятиях.

\section{ПРЕКАРИЗАЦИЯ ЗАНЯТОСТИ МОАОАЕЖИ И МЕЖПОКОАЕНЧЕСКИЙ КОНФАИКТ}

Прекаризацию молодежи как явление можно связать с развитием острых поколенческих конфликтов, действующих в трех социальных плоскостях.

Первую плоскость образует система образования, мощный, исторически сложившийся институт, находящийся под влиянием двух противоположных по направлен- 
ности факторов: необходимости соответствовать современным реалиям экономики и технологии, с одной стороны, а с другой - традиции преподавания устоявшихся, а зачастую устаревших знаний, невозможности быстрого обновления учебного материала и компетенций самих преподавателей. Именно эту систему в наибольшей степени регулирует государство, разрабатывая проекты по созданию профессиональных и учебных стандартов, лицензируя учебные заведения. Преподаватели и обучающиеся теперь - это не просто разные поколения по возрасту, они носители разных целей образовательного процесса. Поколение преподавателей - это идеальные воспроизводители информации, которые много знают наизусть, способны работать без электронных устройств. Обучающиеся не понимают, для чего заучивать информацию, если ее в любой момент можно узнать из Сети, для чего писать от руки, если можно набирать с клавиатуры, и пр.

Вторая плоскость обусловлена подходами работодателей. Они старше поколения «Y», скорее это поколение «Х» или еще старше. Однако именно они быстрее всего в силу рыночной конкуренции реагируют на инновации, поэтому стажеры и выпускники учебных заведений оцениваются ими как носители устаревшего знания и зачастую отбраковываются в процессе найма. Рынок труда становится рынком работодателя, поэтому работодатель будет выбирать готового специалиста, не желая учить или исправлять. Если же наем или стажировка все же происходит, начинается ломка усвоенных навыков труда и поиск информации, которая только усиливает психологическое давление на молодого специалиста, создавая условия для скорого увольнения. Прекаризация, таким образом, усиливается.

Часть әтих обстоятельств привела к тому, что, по данным Роструда за 2015 г., 30,5\% всех российских безработных - это молодые люди в возрасте от 14 до 29 лет. Безработных среди молодежи в России в 5 раз больше, чем среди 30-40-летних (Горелова, 2015: Электронный ресурс).

Третья плоскость - сами молодые специалисты. Им труднее всего. С одной стороны, выходя на рынок труда, они обнаруживают, что внушаемые им многие годы установки не работают и не приносят карьерных и материальных результатов. Старательность в выучивании и воспроизведении содержания учебников, так ценимая во время учебы, не требуется на работе, а самостоятельным системным поиском информации и отработке навыков молодые специалисты не обучены. Здесь конфликт, скорее, не межпоколенческий, а внутриролевой в рамках одного статуса молодого специалиста. Ролевые требования предполагают диплом с отличием, знание учебных дисциплин и соблюдение дресс-кода, в то же время это зачастую не помогает найти работу, а в условиях постиндустриальной занятости еще и демонстрирует нежелание развивать современные навыки. Установки на полную легальную занятость внушаются молодежи предыдущими поколениями, они вступают в противоречие с существующей социально-экономической средой, прежде всего с реалиями рынка труда.

\section{ЗАКАЮЧЕНИЕ}

Общей рекомендацией может стать не только выработка профессиональных компетенций в рамках образовательного процесса, но и реализация проектов в отношении молодежи со стороны работодателей. Это касается проектов по разработке системы поиска перспективных выпускников и организации стажировок. Успешной показывает себя практика взаимодействия работодателей с учебными заведениями Аля целевой подготовки будущих сотрудников. «Такое сотрудничество осуществля- 
ется в форме совместной выработки структуры программы подготовки специалистов вплоть до ученических контрактов с работодателем и обязательного распределения при трудоустройстве» (Коврижкина, 2015: 34).

Таким образом, прекаризация молодежи может быть расценена как негативное явление современного рынка труда. Негативное влияние ее может быть снижено за счет разработки проектов по трансформации образовательного процесса в учебных заведениях для более тесной работы с будущими работодателями. Такие проекты будут развивать взаимодействие профессиональных и бизнес-сообществ по созданию и корректировке профессиональных стандартов и развитию у молодых специалистов надпрофессиональных компетенций, что в конечном счете позволит преодолеть прекаризацию занятости молодежи.

\section{СПИСОК АИТЕРАТУРЫ}

Бобков, В. Н., Бобков, Н. В, Акимов, А. А., Алиев, У. Т. (2015) Прекаризация занятости и регулирование социально-трудовых отношений в России // Неустойчивость занятости (прекаризация): особенное и общее с учетом интеграционных усилий государства и общества / глав. ред. В. Н. Бобков. М. : Издательский дом «Магистр-Пресс». 448 с. С. 8-18.

Горелова, Е. (2015) Безработных среди молодежи в России в 5 раз больше, чем 30-40-летних [Электронный ресурс] // Ведомости. 27 октября. URL: https://www.vedomosti.ru/management/articles/2015/10/27/614577-bezrabotnih-molodezhi (дата обращения: 28.05.2018).

Жвитиашвили, А. Ш. (2016) Новые социальные группы на Западе: общее и особенное // Власть. № 1. С. 118-124.

Зудина, А. А. (2017) «Не работают и не учатся»: NEET-молодежь на рынке труда в России : препринт WP3/2017/02 / М. : Изд. дом Высшей школы экономики. Серия WP3 «Проблемы рынка труда». 21 с. [Электронный ресурс] // Высшая школа экономики. URL: https://wp.hse.ru/ data/2017/04/17/1169031315/WP3_2017_02 .pdf (дата обращения: 14.05.2018).

Калинюк, И. В. (1985) Классификация возраста // Аемографический энциклопедический словарь / глав. ред. А. И. Валентей. М. : Советская энциклопедия. 608 с. С. 243.

Коврижкина, М. М. (2015) Проблема интеграции требований образовательного и профессионального стандарта в области бухгалтерского учета // Экономика и управление развитием в условиях изменений. XXVI научная конференция аспирантов и докторантов / под общ. ред. Е. Б. Крыловой, Ю. Н. Царегородцева. М. : ИзА-во Московского гуманитарного университета. 122 с. С. $27-35$.

Стэндинг, Г. (2014) Прекариат: новый опасный класс. М. : Ад Маргинем Пресс. 328 с.

Федорова, Н. В. (2015) Методологические подходы к исследованию прекаризации занятости. [Электронный ресурс] // Информационный гуманитарный портал «Знание. Понимание. Умение». № 6 (ноябрь - декабрь). URL: http://zpu-journal.ru/e-zpu/2015/6/Fedorova_Employment-Precarisation/ (дата обращения: 28.05.2018)

Федорова, Н. В., Минченкова, О. Ю. (2017) Управление персоналом : учебник для СПО. М. : КноРусс. 245 с.

Elder, S. (2015) What does NEETs mean and why is the concept so easily misinterpreted? [Электронный ресурс] // International Labour Office. URL: http://www.ilo.org/wcmsp5/ groups/public/@dgreports/@dcomm/documents/publication/wcms_343153.pdf (дата обращения: 14.05.2018).

Schott, B. (2008) Strawberry Generation [Электронный ресурс]// The New York Times. November 30. URL: https://schott.blogs.nytimes.com/2008/11/30/strawberry-generation/ (дата обращения: 09.04.2018).

Chou, J. (2005) Strawberry Generation is just a myth, statistics say. [Электронный pecypc] // taipeitimes. URL: http://www.taipeitimes.com/News/taiwan/archives/2005/09/12/2003271331 (дата обращения: 18.03.2018). 
The Neet generation: Why young Britons have been hardest hit by the The Independent (2014) [Электронный ресурс] // Independent . URL: https://www.independent.co.uk/news/uk/politics/ the-neet-generation-why-young-britons-have-been-hardest-hit-by-the-economic-downturn9155640.html (дата обращения: 21.02.2018).

Аата поступления: 12.06 .2018 2.

\author{
PROJECT APPROACH TO SOLVING \\ THE PROBLEMS OF PRECARIZATION OF EMPLOYMENT \\ OF YOUNG PEOPLE \\ N. V. FEDOROVA, M. M. KovRIZHKINA \\ MOSCOW UNIVERSITY FOR THE HUMANITIES
}

The article analyses the issue of part-time work (precarious employment) of Russia' young people, which is currently widespread on the labor market. The youth is not considered as one single generation; it consists of several generation groups. The author defines the following groups of working young adults: the securely employed, successful freelancers, employed but badly-paid young specialists, and the precariously working youth. The latter group's income is hardly enough to make a living. These young people cannot change their professions or places of living; they often possess too little knowledge of laws to find a job and conclude a good contract. Their survival is dependent on their parents, or more successful relatives.

The main feature of this group is their perception of the labor market as unconditionally hostile towards them. Unlike the low-income young people of the past, the contemporary representatives of the lowest precariously employed group are less prone to antisocial behavior, manifesting a low level of political and criminal activity.

The precarization of youth as a phenomenon can be attributed to the development of acute generation conflicts acting in three social dimensions: in the system of education (between teachers and students), in the labor market (between employers and young specialists), and among young people themselves (role conflict).

On the whole, it can be recommended that not only professional competencies should be developed within the educational process, but also that certain measures should be taken by employers. It is related to creating a search system for promising graduates and organizing vocational training sessions. The practice of employees collaborating with educational institutions proves to be successful in professional training of future employees.

To sum up, the precarization of young people can be considered a negative phenomenon of the contemporary labor market. Its negative impact can be reduced by transforming the education process at educational institutions, and also by working more closely with prospective employers. This cooperation is enhanced through the activities of professional and business communities aimed at creating and improving professional standards. It is also conductive to young professionals developing extraprofessional competencies, which will eventually make it possible to overcome precarious employment among young people.

Keywords: project approach; project; precarization; youth; millennials; labor market; employment

\title{
REFERENCES
}

Bobkov, V. N., Bobkov, N. V, Akimov, A. A. and Aliev, U. T. (2015) Prekarizatsiia zaniatosti i regulirovanie sotsial'no-trudovykh otnoshenii v Rossii. In: Neustoichivost' zaniatosti (prekarizatsiia): osobennoe i obshchee suchetom integratsionnykb usilii gosudarstva i obshchestva / ed. by V. N. Bobkov. Moscow, Izdatel'skii dom «Magistr-Press». 448 p. Pp. 8-18. (In Russ.).

Gorelova, E. (2015) Bezrabotnykh sredi molodezhi v Rossii v 5 raz bol'she, chem 30-40-letnikh. Vedomosti, 27 October [online] Available at: https://www.vedomosti.ru/management/articles/2015/10/27/614577-bezrabotnih-molodezhi (access date: 28.05.2018). (In Russ.). 
Zhvitiashvili, A. Sh. (2016) Novye sotsial'nye gruppy na Zapade: obshchee i osobennoe. Vlast', no. 1, pp. 118-124. (In Russ.).

Zudina, A. A. (2017) «Ne rabotaiut i ne uchatsia»: NEET-molodezh' na rynke truda v Rossii : preprint WP3/2017/02. Moscow, Izd. dom Vysshei shkoly ekonomiki. Seriia WP3 «Problemy rynka truda». 21 s. Vysshaia shkola ekonomiki. [online] Available at: https://wp.hse.ru/data/2017/04/ 17/1169031315/WP3_2017_02 .pdf (access date: 14.05.2018). (In Russ.).

Kaliniuk, I. V. (1985) Klassifikatsiia vozrasta. In: Demograficheskii entsiklopedicheskii slovar' / ed. by D. I. Valentei. Moscow, Sovetskaia entsiklopediia. 608 p. P. 243. (In Russ.).

Kovrizhkina, M. M. (2015) Problema integratsii trebovanii obrazovatel'nogo i professional'nogo standarta v oblasti bukhgalterskogo ucheta. In: Ekonomika $i$ upravlenie razvitiem $v$ usloviiakh izmenenii. XXVI nauchnaia konferentsiia aspirantov $i$ doktorantov / ed. by E. B. Krylova and Iu. N. Tsaregorodtsev. Moscow, Izd-vo Moskovskogo gumanitarnogo universiteta. 122 p. Pp. 27-35. (In Russ.). Russ.).

Stending, G. (2014) Prekariat: novyi opasnyi klass. Moscow, Ad Marginem Press. 328 p. (In

Fedorova, N. V. (2015) Metodologicheskie podkhody k issledovaniiu prekarizatsii zaniatosti. Informatsionnyi gumanitarnyi portal "Znanie. Ponimanie. Umenie», no. 6 [online] Available at: http://zpu-journal.ru/e-zpu/2015/6/Fedorova_Employment-Precarisation/ (access date: 28.05.2018)

Fedorova, N. V. and Minchenkova, O. Iu. (2017) Upravlenie personalom : uchebnik. Moscow, KnoRuss. 245 p. (In Russ.).

Elder, S. (2015) What does NEETs mean and why is the concept so easily misinterpreted? International Labour Office [online] Available at: http://www.ilo.org/wcmsp5/groups/public/ @dgreports/@dcomm/documents/publication/wcms_343153.pdf (access date: 14.05.2018).

Schott, B. (2008) Strawberry Generation. The New York Times, November 30 [online] Available at: https://schott.blogs.nytimes.com/2008/11/30/strawberry-generation/ (access date: 09.04.2018). (In Russ.).

Chou, J. (2005) Strawberry Generation is just a myth, statistics say. Taipeitimes [online] Available at: http://www.taipeitimes.com/News/taiwan/archives/2005/09/12/2003271331 (access date: 18.03.2018).

The Neet generation: Why young Britons have been hardest hit by the The Independent (2014) Independent [online] Available at: https://www.independent.co.uk/news/uk/politics/the-neet-generation-why-young-britons-have-been-hardest-hit-by-the-economic-downturn-9155640.html (access date: 21.02.2018).

Submission date: 12.06.2018.

Федорова Наталья Васильевна — кандидат экономических наук, доцент, профессор кафедры менеджмента Московского гуманитарного университета. Адрес: 111395, Россия, г. Москва, ул. Юности, д. 5, корп. 3. Тел.: +7 (499) 374-70-13. Эл. адрес: kafedra612@mail.ru

Коврижкина Мария Михайловна - преподаватель кафедры менеджмента Московского гуманитарного университета. Адрес: 111395, Россия, г. Москва, ул. Юности, д. 5, корп. 3. Тел.: +7 (499) 374-70-13. Эл. aspec: kolibri-hr@yandex.ru

Fedorova Natalya Vasilyevna, Candidate of Economics, Associate Professor, Professor, Department of Management, Moscow University for the Humanities. Postal address: 5, Bldg. 3, Yunosti St., Moscow, Russian Federation, 111395. Tel.: +7 (499) 374-70-13. E-mail: kafedra612@mail.ru

Kovrizhkina Mariya Mihaylovna, Lecturer, Department of Management, Moscow University for the Humanities. Postal address: 5, Bldg. 3, Yunosti St., Moscow, Russian Federation, 111395. Tel.: +7 (499) 374-70-13. E-mail: kolibri-hr@yandex.ru 